\title{
Stroke and transient ischemic attacks related to antiplatelet or warfarin interruption
}

\author{
Acidente vascular cerebral e ataques isquêmicos transitórios relacionados à interrupção \\ de antiplaquetários ou varfarina
}

\author{
Vanessa RIZELIO', Andre Luiz Borba MACUCO'1, Henry Koiti SATO', Maria Tereza de Moraes Souza
}

NASCIMENTO', Ricardo Krause Martinez de SOUZA', Pedro André KOWACS ${ }^{1,2}$

\begin{abstract}
Patients on anticoagulant or antiplatelet therapy are often required to discontinue these medications before and during surgical or invasive procedures. In some cases, the patient stops the treatment without medical supervision. These situations may increase stroke risk. Objective: To identify the ischemic stroke and transient ischemic attack (TIA) prevalence related to length of time of discontinuation of antiplatelet or vitamin K antagonist therapy, in a group of inpatients from a specialized neurological hospital in Brazil. Methods: Crosssectional, retrospective and descriptive study of stroke inpatients for three years. Medical reports were reviewed to find study participants, stroke characteristics, risk factors, reasons and time of drug interruption. Results: In three years, there were 360 stroke and TIA inpatients, of whom $27(7.5 \%)$ had a history of antiplatelet or vitamin $\mathrm{K}$ antagonist interruption correlated with the time of the event (81\% ischemic stroke, $19 \%$ TIA). The median time between antiplatelet interruption and an ischemic event was five days, and $62 \%$ of events occurred within seven days after drug suspension. For vitamin Kantagonists, the average time to the ischemic event was 10.4 days (SD = 5.7), and in 67\% of patients, the time between drug discontinuation and the event was 7-14 days. The most frequent reason for drug suspension was patient negligence (37\%), followed by planned surgery or invasive examination (26\%) and side effects, including hemorrhage (18.5\%). Conclusion: Antiplatelet or vitamin $\mathrm{K}$ antagonist suspension has a temporal relationship with the occurrence of stroke and TIA. Since these events are preventable, it is crucial that healthcare professionals convince their patients that drug withdrawal can cause serious consequences.
\end{abstract}

Keywords: Stroke; ischemic attack, transient; anticoagulants; compliance.

\section{RESUMO}

Pacientes em terapia anticoagulante ou antiagregante plaquetária frequentemente são solicitados a descontinuar essas medicações antes e durante procedimentos cirúrgicos ou invasivos. Se o paciente interromper tratamento sem supervisão médica, poderá aumentar de risco de acidente vascular cerebral (AVC). Objetivo: Identificar prevalência de AVC isquêmico e ataque isquêmico transitório (AIT) associados à descontinuação de terapia antiplaquetária ou coumarínicos em pacientes internados em hospital especializado em atendimento neurológico no Brasil. Métodos: Estudo transversal, retrospectivo de três anos, descritivo dos pacientes hospitalizados por AVC. A revisão de relatórios médicos determinou características do AVC, fatores de risco, motivos e tempo de interrupção medicamentosa. Resultados: Em três anos, foram internados 360 pacientes por AVC ou AIT; destes, 27 interromperam temporariamente terapia antiplaquetária ou coumarínicos relacionando ao evento ( $81 \%$ acidente vascular cerebral isquêmico, 19\% AIT). A prevalência foi de 7,5\%. 0 tempo médio entre interrupção antiplaquetária e evento foi cinco dias, com $62 \%$ deles ocorrendo até sete dias após suspensão medicamentosa. Para coumarínicos, o tempo médio foi 10,4 dias (d.p.= 5,7), em 67\% dos casos o tempo entre a descontinuação medicamentosa e o evento foi 7-14 dias. 0 motivo mais frequente para suspensão do medicamento foi negligência do paciente (37\%), seguido por cirurgia planejada ou exame invasivo (26\%) e efeitos colaterais, incluindo hemorragia (18,5\%). Conclusão: Suspensão de terapia de antiplaquetários ou coumarínicos tem relação temporal com ocorrência de AVC e de AIT. Esses eventos são passíveis de serem evitados, sendo imprescindível que profissionais de saúde convençam seus pacientes das consequências graves da retirada do medicamento.

Palavras-chave: Acidente vascular cerebral; ataque isquêmico transitório; anticoagulantes; complacência (medida de distensibilidade).

Patients taking antithrombotic therapy for vascular risk reduction are often asked to discontinue these drugs before and during surgical or invasive procedures ${ }^{1}$. In high risk patients, bridging therapy may be indicated ${ }^{2}$. The initial

${ }^{1}$ Instituto de Neurologia de Curitiba; Curitiba PR, Brasil;

¿Universidade Federal do Paraná, Curitiba PR, Brasil.

Pedro André Kowacs (iD) https://orcid.org/0000-0001-7770-7475

Correspondence: Pedro André Kowacs; Rua Jeremias Maciel Perretto, 300; 81210-310 Curitiba PR Brasil; E-mail: pkowacs@gmail.com

Conflicts of Interest: Vanessa Rizelio: Financial assistance provided by Roche, Pfizer, Lilly, Bial and Boehringer-Ingelheim. André Luiz Borba Macuco, Henry Koiti Sato, Maria Tereza de Moraes Souza, Ricardo Krause Martinez de Souza and Pedro André Kowacs: None.

Received 29 October 2018; Accepted 14 February 2019. 
treatment should be resumed as soon as possible after the surgery or invasive procedure ${ }^{1}$. However, in some cases the treatment is stopped at the patient's will, without medical supervision, because of adverse events, drug interactions, dementia or neglect ${ }^{2}$.

In this study we aimed to identify, among stroke patients, the prevalence of cases in which such events had a temporal association with discontinuation of antiplatelet or anticoagulant therapy. The factors that led to drug interruption and the interval between discontinuation and stroke were investigated in the study.

\section{METHODS}

This was a cross-sectional, retrospective, descriptive study of a sample of acute stroke patients hospitalized in a neurological hospital in Brazil, between 2007 and 2009. We included patients with a diagnosis of ischemic stroke or transient ischemic attack (TIA) whose medical history indicated that interruption of antiplatelet or oral anticoagulant agents was time-related to the occurrence of stroke. Hemorrhagic strokes were not included.

Demographic and clinical data were collected from the medical records (Table 1). For antithrombotic therapy, we investigated the class and dosage of anticoagulant or antiplatelet, reason for treatment discontinuation and time interval between drug interruption and the occurrence of the ischemic event.

Arterial hypertension was defined as arterial blood pressure greater than 140 / 90 mmHg. Diabetes mellitus was defined as a fasting glucose serum level greater than $126 \mathrm{mg} / \mathrm{dL}$. Hypercholesterolemia was defined as a total fasting cholesterol serum level of greater than $200 \mathrm{mg} / \mathrm{dL}$.

Table 1. Demographic and clinical features.

\begin{tabular}{lc}
\hline Age in years & $68 \pm 12.7$ \\
\hline Sex & $\%$ \\
Male & 48 \\
Female & 52 \\
Vascular risk factors & $\%$ \\
Arterial hypertension & 88.8 \\
Hypercholesterolemia & 62.9 \\
Atherosclerotic carotid disease & 62.9 \\
Previous stroke or transient ischemic attack & 48.1 \\
Positive cardiovascular history & 48.1 \\
Atrial fibrillation & 33.3 \\
Smoking & 29.6 \\
Diabetes mellitus & 18.5 \\
Patent foramen ovale & 11.1 \\
Therapy interrupted & $\%$ \\
Aspirin (*) & 55.5 \\
Clopidogrel & 18.5 \\
Warfarin & 26 \\
\hline There was one patient on concomitant aspirin and warfarin treatment.
\end{tabular}

Smoking was classified as present or absent on admission to hospital. Positive cardiovascular history was defined as the presence of one or more of the following in the medical history: acute myocardial infarct, unstable angina, coronary angioplasty, myocardial revascularization surgery and other embolic cardiopathies, such as Chagas disease, dilated myocardiopathy and valve prosthesis.

A descriptive statistical analysis was carried out, data are expressed as mean \pm standard deviation and prevalence, using Microsoft" Excel" software.

\section{RESULTS}

In the study period, there were 370 admissions due to stroke or TIA. We identified 27 cases $(7.5 \%)$ with a present history of antiplatelet or anticoagulant drug interruption that was time-related to the event ( $81 \%$ ischemic strokes and 19\% TIAs). Stroke clinical data are shown in Table 2. Patients were taking antithrombotic drugs to reduce cardiovascular risk (54.8\%) or for stroke prevention (48.2\%). Table 3 summarizes the patients' reasons for discontinuing therapy.

The median time between interruption of antiplatelet therapy (aspirin and clopidogrel) and an ischemic event was five days (range $=3$ to 120 ). In $62 \%$ of the patients, stroke or TIA occurred within seven days of interruption of therapy. For vitamin $\mathrm{K}$ antagonists, the mean time between interruption of therapy and an ischemic event was 10.4 days \pm 5.7 (range $=2$ to 15 ) and, in $67 \%$ of the patients, the time between drug discontinuation and an ischemic event ranged from 7-14 days.

Table 2. Stroke classification.

\begin{tabular}{lc}
\hline BAMFORD clinical classification & $\%$ \\
\hline Partial anterior circulation stroke & 55.0 \\
Lacunar stroke & 30.0 \\
Posterior circulation stroke & 15.0 \\
\hline TOAST etiologic classification & $\%$ \\
\hline Cardioembolism & 33.0 \\
Large artery atherosclerosis & 26.0 \\
Small-vessel occlusion & 11.0 \\
Undetermined etiology* & 30.0 \\
\hline *All had two or more causes identified. &
\end{tabular}

Table 3. Reasons for discontinuation of antithrombotic therapy.

\begin{tabular}{lc}
\hline Reason & $\%$ \\
\hline Patient's negligence & 37.0 \\
Planned surgery or invasive examination & 26.0 \\
Side effects (including hemorrhage) & 18.5 \\
Not assessed & 11.1 \\
Other* & 7.4 \\
\hline *Other includes one patient with clopidogrel interruption for anticoagulation \\
bridging therapy and one patient on dual antiplatelet therapy, in whom one \\
drug was stopped three months after coronary angioplasty and stenting.
\end{tabular}


By discharge, $41 \%$ had resumed to their original treatment, $38 \%$ were changed to dual antiplatelet therapy, $31 \%$ changed antiplatelet agent and $31 \%$ changed to an oral anticoagulant.

\section{DISCUSSION}

\section{Why is treatment sometimes interrupted?}

In the present study, we observed that there was a considerable proportion $(7.5 \%)$ of patients in whom stroke was not only time-related to warfarin interruption but also to the withdrawal of antiplatelet drugs. In these patients, the antithrombotic drug withdrawal may have contributed to the event. Aspirin interruption has already been shown to be a risk factor for the occurrence of acute myocardial infarction ${ }^{3}$ and stroke ${ }^{2}$. A large study on low-dose acetylsalicylic acid interruption revealed that, in the stroke group, nonadherence was the main cause of acetylsalicylic acid discontinuation, followed by treatment change ${ }^{4}$.

Maulaz et al. ${ }^{2}$ showed, in a case-control study of aspirin users, that drug interruption had an odds ratio of $3.4 \%$ for ischemic cerebrovascular events. The reasons they identified for the interruption of therapy (planned invasive procedures, side effects including bleeding and nonadherence to the treatment) were present in similar proportions to those described in the present study. Our findings revealed that patient negligence was the main reason for stopping the therapy. Failure to adhere to the therapy may be due to inadequate medical guidance on the importance of treatment, but high drug costs may also explain some cases. Treatment adherence must be reinforced with patients ${ }^{4}$, particularly the elderly and those on polypharmacy-groups susceptible to adverse events-in whom treatment interruption without medical guidance is more likely ${ }^{5}$.

The most important reason for discontinuing antiplatelet or anticoagulant therapy before invasive procedures is the risk of hemorrhage. A recent survey on a population in whom $62 \%$ of the interviewed were on antithrombotic therapy, found that $10 \%$ of the participants had stopped taking their medications, either anticoagulants (20\%) or antiplatelets (9\%), within 60 days prior to a medical intervention. The study also found antiplatelet drugs to be discontinued mainly for colonoscopies and orthopedic surgeries, and anticoagulant withdrawal mostly for orthopedic and vascular surgeries ${ }^{6}$.

When a patient on an antithrombotic drug requires interruption for an invasive procedure, we should evaluate at least three points: 1) hemorrhagic risk of surgery; 2) patient vascular risk (ischemia or thrombosis); and 3) renal function in patients taking non-vitamin $\mathrm{K}$ direct anticoagulants ${ }^{7,8}$. In high-risk patients taking a vitamin $\mathrm{K}$ antagonist, subcutaneous low-molecular-weight heparin therapy should be considered $^{9}$. A literature review by Ayoub et al. ${ }^{10}$, from trials of heparin or low-molecular weight heparin bridging in atrial fibrillation patients, who required temporary vitamin
K antagonist interruption for surgery or procedure, showed increased risk of periprocedural hemorrhage, but no difference in mortality compared with patients who had not received bridging therapy.

\section{Does interruption of anticoagulant and antiplatelet drugs have a prothrombotic effect?}

Submission of a patient with prothrombotic conditions to a surgical procedure, which in itself promotes a hypercoagulable state ${ }^{1}$, could increase the risk of an ischemic event. After interruption of aspirin or clopidogrel, a stroke or TIA may be explained not only by the new platelets pool but also by a prothrombotic rebound effect ${ }^{2,11}$. After discontinuation of clopidogrel, normal platelet function returns after seven days $^{12}$. However, an impedance-induced platelet aggregation sequential study on whole blood taken from 28 coronary stented patients, in whom clopidogrel was interrupted abruptly after a year of continuous use, found platelet hyperreactivity in more than half of the patients from week two to week six, thus suggesting patients who withdrew from clopidogrel to be at an even greater risk ${ }^{11}$.

In the present study, the majority $(62 \%)$ of the events occurred within seven days of antiplatelet interruption, corroborating the theory of a prothrombotic effect after interruption of this therapy.

A 2011 study on the interruption of low-dose antiplatelet therapy for the prevention of ischemic stroke or myocardial infarction in a cohort of 39,512 selected patients followed for an average of 3.42 years, found that interruption of acetylsalicylic acid lead to a $40 \%$ increase in the risk of ischemic stroke or TIA. The risk was higher among the recent discontinuers (1-15 days) ${ }^{4}$.

Another cohort study done using a five-year Danish stroke registry correlated antiplatelet therapy discontinuation with increased risk of ischemic stroke ${ }^{13}$. Increased prothrombotic activity also occurred after warfarin interruption, resulting in increased thrombin production and platelet activation ${ }^{14}$.

A more recent study on the risk of ischemic stroke in high risk atrial fibrillation patients 65 years old or older, with at least one additional risk factor for ischemic stroke, in whom warfarin was discontinued for surgical procedures, showed a higher rate of ischemic stroke in the warfarin-discontinued group ( $1.1 \%$ of 265 versus $0.4 \%$ of 71,355$)$, a population attributable risk of $23.1 \%^{15}$.

Another study on 27,000 nonvalvular atrial fibrillation patients found that interruptions of warfarin for 45 days or longer, significantly increased the chance of a cerebrovascular ischemic event or a TIA ${ }^{16}$.

\section{Study pitfalls}

This study has a number of limitations because of the absence of a control group (patients who discontinued the use of medications and did not have stroke or TIA). However, the objective of this analysis was not to compare our series with a control group but to point out that the risk of ischemic 
events in patients who interrupt antiplatelet or vitamin $\mathrm{K}$ antagonist therapy is real and should not be overlooked. Patients taking non-vitamin $\mathrm{K}$ antagonist direct anticoagulants were not included in this study because the drugs were not used in Brazil by the time of data collection.

In conclusion, based on our results, we recommend that clinicians should be aware of antithrombotic therapy interruption before a stroke or TIA and verify any possible relationship to the event. Furthermore, patients should be informed about risks of inadequate interruption of antiplatelet or anticoagulant drugs. In high vascular risk patients, heparin or low-molecular weight heparin bridging therapy may be considered, but should be balanced against the periprocedural hemorrhagic risk.

\section{References}

1. Douketis JD, Johnson JA, Turpie AG. Low-molecular-weight heparin as bridging anticoagulation during interruption of warfarin: assessment of a standardized periprocedural anticoagulation regimen. Arch Intern Med. 2004 Jun;164(12):1319-26. https://doi.org/10.1001/archinte.164.12.1319

2. Maulaz AB, Bezerra DC, Michel P, Bogousslavsky J. Effect of discontinuing aspirin therapy on the risk of brain ischemic stroke. Arch Neurol. 2005 Aug;62(8):1217-20. https://doi.org/10.1001/archneur.62.8.1217

3. Rodríguez LA, Cea-Soriano L, Martín-Merino E, Johansson S. Discontinuation of low dose aspirin and risk of myocardial infarction: case-control study in UK primary care. BMJ. 2011 Jul;343 jul19 1:d4094. https://doi.org/10.1136/bmj.d4094

4. García Rodríguez LA, Cea Soriano L, Hill C, Johansson S. Increased risk of stroke after discontinuation of acetylsalicylic acid: a UK primary care study. Neurology. 2011 Feb;76(8):740-6. https://doi.org/10.1212/WNL.0b013e31820d62b5

5. De Schryver EL, Gijn J, Kappelle LJ, Koudstaal PJ, Algra A. Non-adherence to aspirin or oral anticoagulants in secondary prevention after ischaemic stroke.J Neurol. 2005 Nov;252(11):1316-21. https://doi.org/10.1007/s00415-005-0858-0

6. Wagner ML, Khoury JC, Alwell K, Rademacher E, Woo D, Flaherty $\mathrm{ML}$, et al. Withdrawal of antithrombotic agents and the risk of stroke. J Stroke Cerebrovasc Dis. 2016 Apr;25(4):902-6. https://doi.org/10.1016/j.jstrokecerebrovasdis.2016.01.006

7. Armstrong MJ, Gronseth G, Anderson DC, Biller J, Cucchiara B, Dafer R, et al. Summary of evidence-based guideline: periprocedural management of antithrombotic medications in patients with ischemic cerebrovascular disease: report of the Guideline Development Subcommittee of the American Academy of Neurology. Neurology. 2013 May;80(22):2065-9. https://doi.org/10.1212/WNL.0b013e318294b32d

8. Veen JJ, Makris M. Management of peri-operative anti-thrombotic therapy. Anaesthesia. 2015 Aug;70(Suppl 1):58-67. https://doi.org/10.1111/anae.12900

9. Douketis JD, Spyropoulos AC, Spencer FA, Mayr M, Jaffer AK, Eckman $\mathrm{MH}$, et al. Perioperative management of antithrombotic therapy: Antithrombotic Therapy and Prevention of Thrombosis, 9th ed:American College of Chest Physicians Evidence-Based Clinical Practice Guidelines. Chest. 2012 Feb;141(2 Suppl):e326S-50S. https://doi.org/10.1378/chest.11-2298PMID:22315266

10. Ayoub K, Nairooz R, Almomani A, Marji M, Paydak H, Maskoun W. Perioperative Heparin bridging in atrial fibrillation patients requiring temporary interruption of anticoagulation: evidence from meta-analysis. J Stroke Cerebrovasc Dis. 2016 Sep;25(9):2215-21. https://doi.org/10.1016/j.jstrokecerebrovasdis.2016.04.006

11. Diehl P, Halscheid C, Olivier C, Helbing T, Bode C, Moser M. Discontinuation of long term clopidogrel therapy induces platelet rebound hyperaggregability between 2 and 6 weeks post cessation. Clin Res Cardiol. 2011 Sep;100(9):765-71. https://doi.org/10.1007/s00392-011-0310-7

12. Weber AA, Braun M, Hohlfeld T, Schwippert B, Tschöpe D, Schrör K. Recovery of platelet function after discontinuation of clopidogrel treatment in healthy volunteers. $\mathrm{Br} \mathrm{J}$ Clin Pharmacol. 2001 Sep;52(3):333-6. Available from: https://doi.org/https://doi.org/10.1046/j.0306-5251.2001.01453.x

13. Ostergaard K, Pottegård A, Hallas J, Bak S, dePont Christensen R, Gaist D. Discontinuation of antiplatelet treatment and risk of recurrent stroke and all-cause death: a cohort study. Neuroepidemiology. 2014;43(1):57-64. https://doi.org/10.1159/000365732

14. Grip L, Blombäck M, Schulman S. Hypercoagulable state and thromboembolism following warfarin withdrawal in post-myocardial-infarction patients. Eur Heart J. 1991 Nov;12(11):1225-33. https://doi.org/10.1093/eurheartj/12.11.1225

15. Qureshi Al, Jahangir N, Malik AA, Afzal MR, Orfi F, Suri MF. Risk of ischemic stroke in high risk atrial fibrillation patients during periods of warfarin discontinuation for surgical procedures. Cerebrovasc Dis. 2016;42(5-6):346-51. https://doi.org/10.1159/000446406

16. Spivey CA, Liu X, Qiao Y, Mardekian J, Parker RB, Phatak H, et al. Stroke associated with discontinuation of warfarin therapy for atrial fibrillation. Curr Med Res Opin. 2015 Nov;31(11):2021-9. https://doi.org/10.1185/03007995.2015.1082995 